\title{
Software Support for Materials-related Active Learning
}

\section{Dr. Kaitlin Tyler, ANSYS Inc.}

Kaitlin is currently an Education Fellow with the Granta Education Division at ANSYS. She received her $\mathrm{PhD}$ at the University of Illinois Urbana Champaign under Professor Paul Braun. Her research was split: focusing on manipulating eutectic material microstructures for optical applications and examining how engineering outreach programs influence participants' self-perceptions of engineering and self-confidence. Her interests lie in materials education and STEM outreach.

\section{Dr. Claes Fredriksson, ANSYS Granta}

Currently working as Senior Materials Education Consultant at ANSYS Granta in Cambridge, UK. Previously Program Director for a Master's Programme in Manufacturing Engineering at University West in Sweden. Experience in teaching subjects like Materials Science \& Technology and Environmental Technology to students of mechanical engineering at the department of Engineering Science since 1999.

\section{Dr. Kaitlin Tyler, ANSYS}




\title{
Software Support for Materials-Related Active Learning
}

\begin{abstract}
The world of education is ever expanding, and with it, our understanding of how people learn. By helping the students connect to their prior knowledge during the formal education in a structured course, the educators can help the students build a more complete comprehension of the topic. Active learning, as a broad term, serves to engage students in the course material in a variety of ways, thereby increasing the probability of connecting with prior knowledge and improving their overall subject understanding. Due to its nature, active learning is necessarily a broad field. There is no one size fits all; different approaches work for different students with different learning styles, subjects, teachers, classrooms, countries and cultural orientations. How can we incorporate active learning methods in teaching materials science and engineering to undergraduates across the globe?

At Ansys Granta, we are interested in understanding how active learning methods are used across the world in materials science courses. For over 25 years, we have been supporting materials education globally through our software GRANTA EduPack. During that time, we have seen how teaching has evolved and the impact active learning techniques have had for materials education. In this paper, we will be sharing how materials teaching with active learning varies around the world and how GRANTA EduPack and its associated resources can support these efforts. We hope this insight gained over many years can aid those looking to adjust their materials courses to include more active learning techniques.
\end{abstract}

\section{Introduction}

We as a community of educators now have an increased understanding of how people learn, and are moving away from the "traditional lecture" model and moving towards more student-centric teaching models [1], such as active learning. The idea of active learning, or actively including students in the teaching and learning processes, is not new and has been discussed for a long time [2]. While the benefits of active learning have been widely recognized [3]-[7], implementation can often be met with resistance. STEM fields offer a source of resistance, where the lecture model often seems the best due to the sheer volume of theoretical information being taught in any given class.

Besides the evolving discussions in active learning, a shift in higher education has come into focus within engineering disciplines. What industries are looking for in college graduates is also evolving; emphasis on more than just technical knowledge: communication, teamwork, and other professional skills are in high demand. Such a shift has occurred that ABET, the accreditation board used by many universities worldwide, has adapted its student outcomes and design definitions to include these topics as fundamental to engineering degrees [8].

Materials science and engineering (MSE) as a discipline is also evolving. What started out as metallurgy and ceramics has now evolved to include polymers, electronic materials, and biomaterials. The field has become more interdisciplinary, with simulation and software programs are now an integral part of the curriculum. Despite all these changes, degrees take the same length of time. Since technical information is being stored digitally, either online or in 
various software packages, the need to understand how to access them and how to use them is higher than ever. With the changes in higher education at large and within the MSE community, how do we keep up? We at Ansys Granta hope to empower educators to make such changes in their courses.

Granta Design was founded 25 years ago by Professors Ashby and Cebon out of the University of Cambridge with the goal of using computers to assist the teaching of materials. Granta Design, now a wholly owned subsidiary of Ansys, was designed to provide students with an interactive way to explore materials data, build materials understanding, and undertake materials selection in a highly visual manner. The company has since evolved to cover Materials Intelligence through software at all levels: from academia to industry. In 2019, it was acquired by an engineering simulation company, which has expanded the focus to include materials information for simulations of all kinds.

In this paper, strategies on how to enable active learning usage in materials science courses via software and connected resources will be discussed. First, a brief overview of knowledge transfer, teaching methods, and active learning will be provided for motivation of the work. Then, a description of the software and the resources provided to support the community of materials educators will be given. Use cases, when applicable, will be referenced. Finally, goals and the next steps for resource support for the materials education community will be shared.

\section{Background}

\section{Lecture: A Higher Education Tradition}

Lectures are a firm fixture within higher education teaching styles. That was often how current lecturers were taught, and many professors feel that this traditional method is what they should be using today. The key to a good lecture is the lecturer themselves; by engaging with the audience, a lecture can provide specifically tailored information for the course to a hall full of students [4]. While good lectures can inspire students, bad lectures can leave a lasting negative impression. This teaching style often relies on the idea that a student's mind is like a spongecapable of simply absorbing knowledge provided to it. But our understanding of how people learn has evolved. The "brain = sponge" school of thought is no longer widely accepted; instead, knowledge is constructed where people use their existing comprehension of the world around them to assimilate new data into a larger understanding [9]. One can think of the learning process like weaving, as shown in Figure 1. With sound previous topic knowledge or basis, new connections can more readily be made (Figure 1a). While curriculums are designed so course content build upon one another, outside forces (i.e. scholarships, co-ops, scheduling conflicts) can cause courses to be taken out of order. This can lead to an incomplete or even incorrect previous topic understanding (Figure 1b), leading to overall decreased learning and more frustration for the student. 
Previous Student

Topic Knowledge

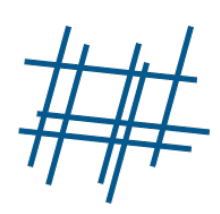

New Student

Topic Knowledge

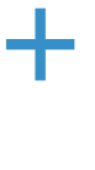

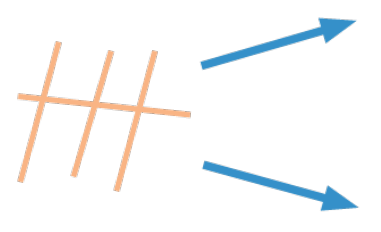

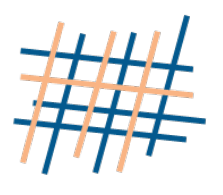

(a) Ideal Learning Process:

Previous Knowledge acts as a Scaffold

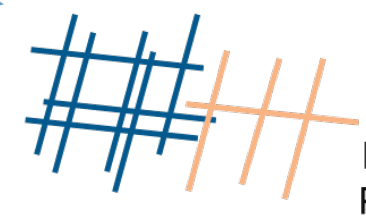

(b) Non-Ideal Learning

Process: Disconnect between Previous and New Knowledge

Figure 1: Learning like Assembling a Quilt

(a): The ideal process, where previous knowledge is connected

(b): The non-ideal process, where previous knowledge is disconnected

It is our job as instructors to consider students' previous learning experiences, both formal and informal, and meet them where their comprehension lies. This can be quite difficult to do in a standard lecture classroom model. With this insight into our students' mindset comes the knowledge that college instruction needs to evolve and adapt. A move towards more learnercenter classrooms has begun, with the focus on transitioning to active learning at the front.

(a) Passive
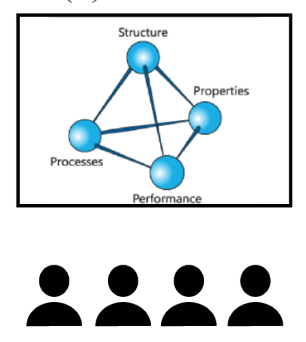

(b) Active
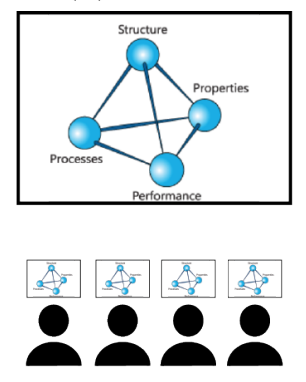

(c) Constructive
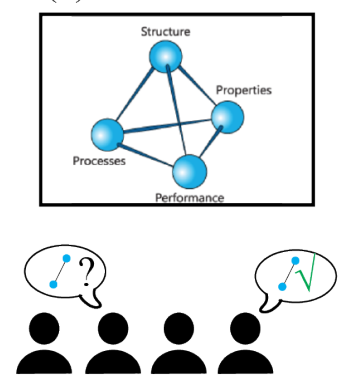

(d) Interactive

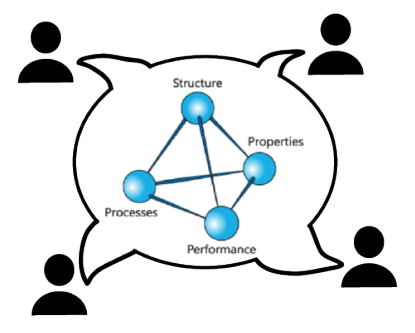

Low

Level of Student Engagement

Figure 2: Learning Activity Categories and their Relative Student Engagement Level [1]

\section{Active Learning}

The definition of active learning used in this paper is: Any instructional method that engages students in the learning process [3]. While this is a very broad definition, it also showcases the versatility of active learning. When talking about student engagement in the classroom, we can categorize activities into four levels [1], as shown in Figure 2. This classification will be used to describe activities in later sections of this paper. 
The least engaging of these levels are Passive Activities. This is where seminars and, often, lectures are categorized (Figure 2a). Active Activities occur when students are doing something while learning, often something physical. This can be as simple as taking notes (Figure 2b) or using clickers to engage with the course material during a lecture. Constructive Activities occur when the learner produces additional outputs beyond what is being taught in class, such as linking topics together or justifying responses in class (Figure 2c). The most engaging level is Interactive Activity. These involve dialogue within a group around the topic of interest. It can be everything from student's discussion with professors or teaching assistants to student-only groups, both in and out of class (Figure 2d).

Considering our definition of active learning, the engagement level should fall between active and interactive. A wide range of classroom activities can lie within that range[6], [10]-[13]. The variety allows for faculty to include activities that will benefit their class: enrollment number, classroom size/style, and course content.

The evidence supporting the use of such active learning strategies in the classroom, even in a minor way, is well known in the community. Technical scholarly and professional skill improvements [4], [14], [15], improved general student motivation and attitudes [16], [17], increasing retention in introductory courses [18] have been seen. But, as with any change in teaching, there are challenges. Due to how commonplace the lecture model is, students often meet anything new or different with resistance [6], [16]. Transparency with students and the motivations behind classroom activities, particularly those well outside the standard lecture that they might be familiar with, can help overcome these challenges. People are generally more motivated to participate in something different when they understand how it could benefit them and our students are no exception. Resistance can also come from the faculty themselves. As mentioned earlier, many faculty were taught with lectures; they are an institution in higher education for a reason [4]. Why change the system that has taught so many people for so many years? Other faculty are more open to adding active learning into their classrooms but can feel overwhelmed by the prospect. Changing a course can be a daunting task and finding the time to overhaul a course while running research groups and doing committee work is no small feat. Even with proper prep time, making changes can take multiple iterations to become a comfortable teaching style. General descriptions of activities can be found throughout the literature but finding specific resources tailored to one's discipline can be challenging. In the field of materials science, engineering, or design, an interactive software tool might be a useful platform.

\section{GRANTA EduPack Active Learning Support through Software and Resources} GRANTA EduPack (formerly CES EduPack) has been designed with materials exploration in mind [19], [20]. By focusing on visualization of data (Figure 3) and strong links between materials and their processing methods (Figure 4), students can begin to build their own materials understanding or intuition. Different databases have been created with curated datasets and tools depending on the discipline, ranging from aerospace to sustainability to bioengineering. Two new databases have been added in 2020 focused on medical devices and their connection to materials and product design. 


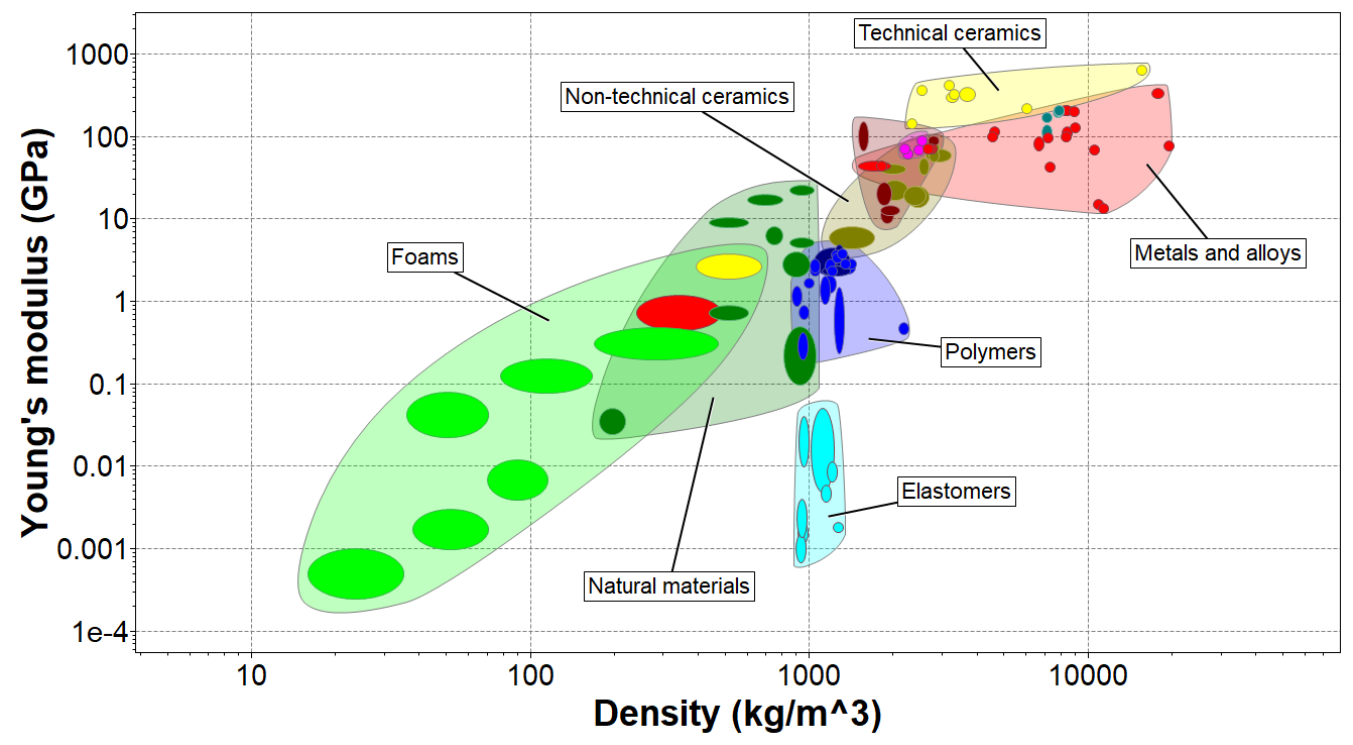

Figure 3: A property chart showcasing the relationship between Stiffness (Young's Modulus) and Density. Students can create similar plots for a variety of material properties, allowing selfexploration of property relationships and material class trends

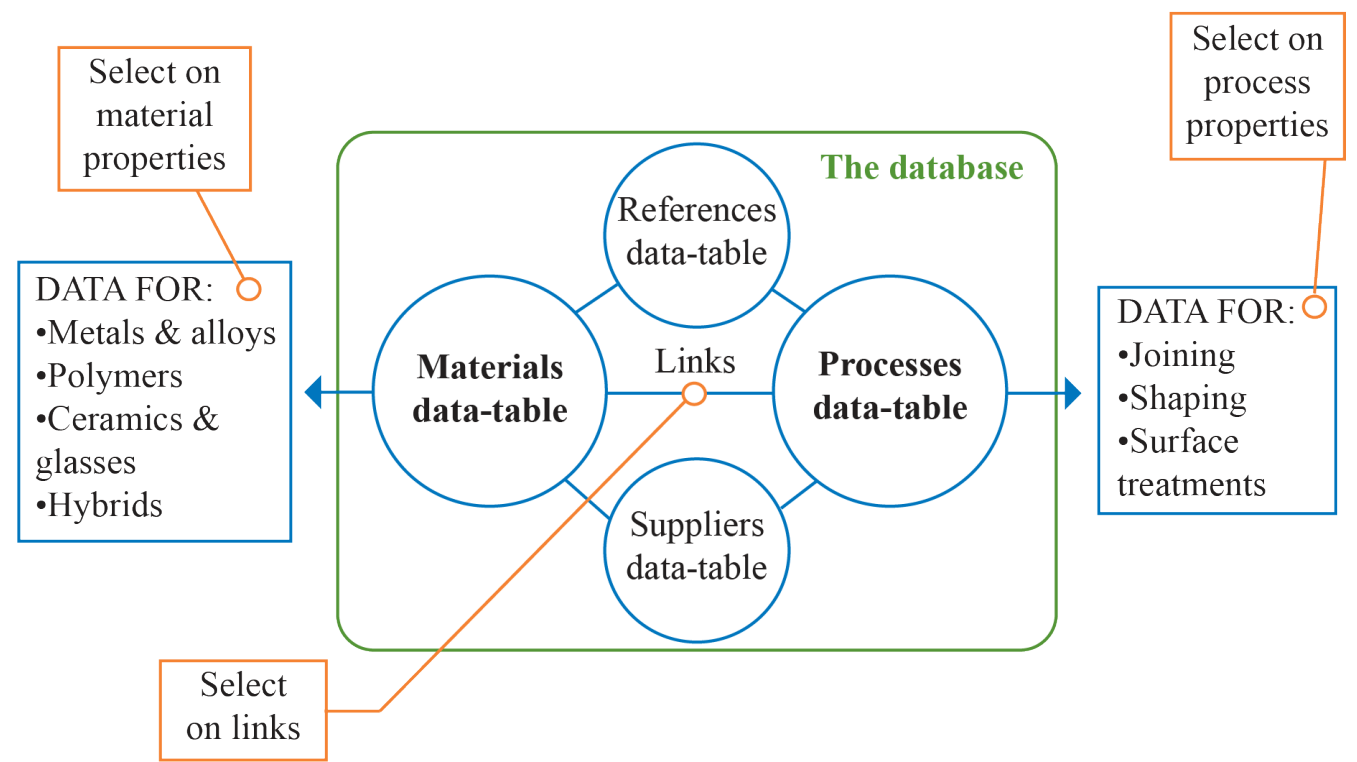

Figure 4: The relationship between the material properties and manufacturing processing within the GRANTA EduPack databases. The links show the multiple paths to reach information within the software, facilitating interactive problem solving in the classroom.

The MS\&E database in the software in particular has been created to support introductory materials science courses [21]. The materials science tetrahedron lies at its core, with six focus areas for students to explore (Figure 5). The Phase Diagram icon is of a particular interest for active learning. As phase diagrams are often a challenging yet integral part of introductory materials courses, interactive tools have been included in the software to demonstrate key concepts such as the Lever Rule (Figure 6) and microstructural evolution upon cooling (Figure 7). 


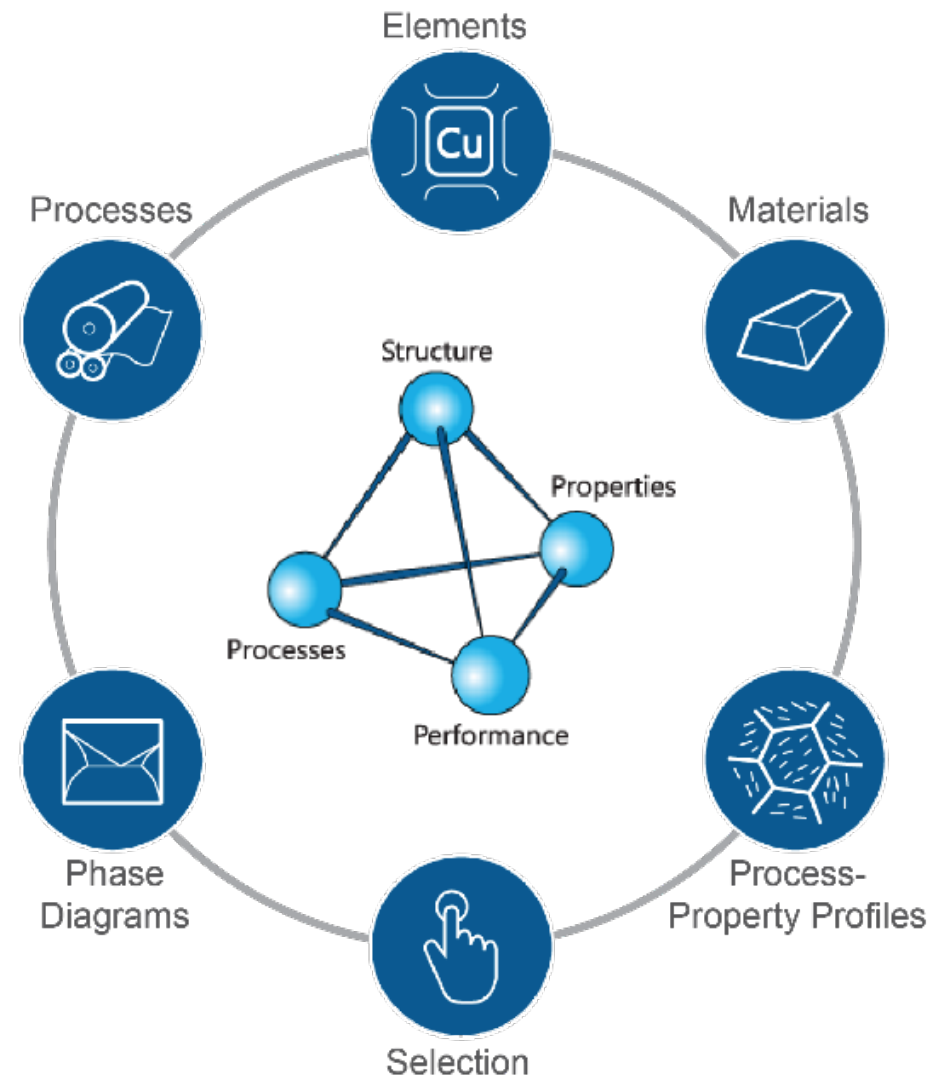

Figure 5: The MS\&E Database Homepage. The tetrahedron is prominent, showcasing the relevant connections.

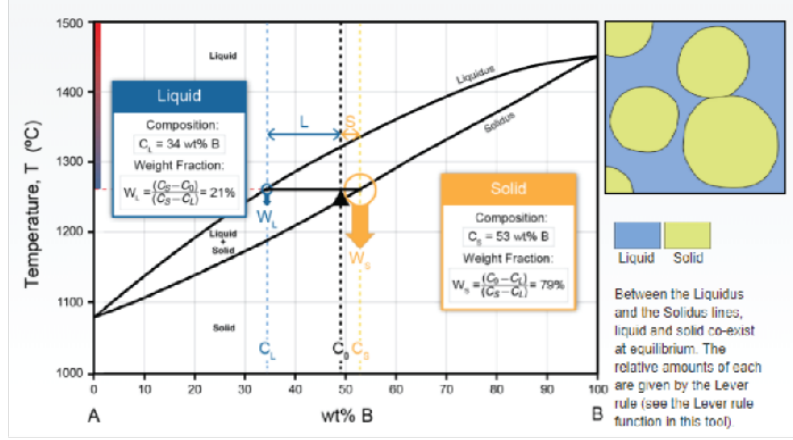

\section{Key points:}

- Three different demonstrations of the Lever Rule for each point

1. Equations with corresponding labels on the diagram

2. Microstructural schematic of phase fraction

3. Graphical drawing of tie line and important points on the line

- Multiple temperature points highlighted to build understanding of phase fraction changes during solidification

- Simple example of isomorphous phase diagram to build basic understanding " Link to more advanced examples within the textbook, classroom, and homework

Figure 6: The Lever Rule Tool Interface and Key Points 


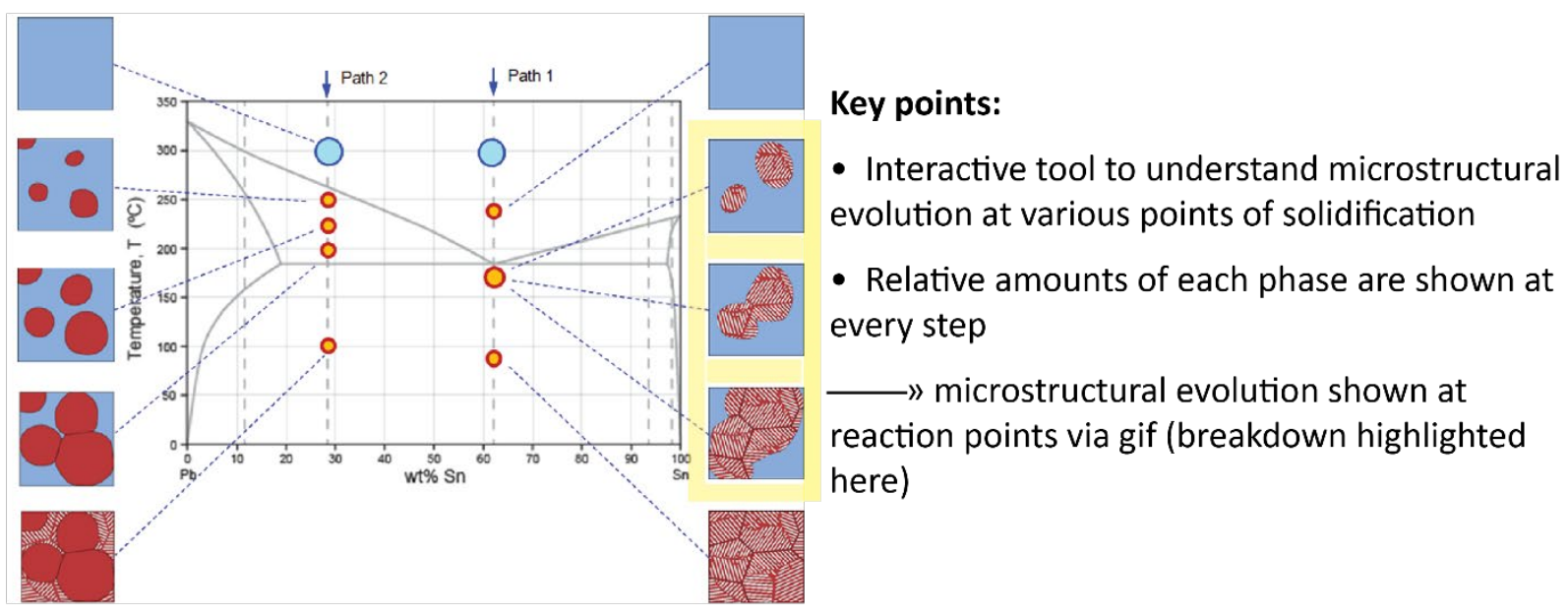

Figure 7: Cooling Paths Interface and Key Points

These tools, combined with the fundamental design of GRANTA EduPack allow for an increased level of student engagement, indicative of active learning. The software itself is used in over 1,400 universities worldwide [22] and has been studied for its efficacy in supporting educators for a variety of course outcomes, including meeting accreditation criteria [23]. To further support implementation of active learning tools within the classroom, we in the Ansys Granta Education Division team work to develop a wide range of resources, available on our website (link included in final draft). Many are open and available for free download. Any resource that contains answers to questions and problems require a software license to download to prevent student access. For this paper, we will be focusing on three resource categories: (i) real-world inspired case studies, (ii) the Five Step Method for advanced design problems, and our newest resource, (iii) Introductory Materials Science Teaching Packages. These resources have been designed with increased student engagement in mind.

Case Studies are among one of the resources categories that we have developed. These resources allow students to see what goes into the design and assessment of real-world products. This realworld connection is critical; it connects to previous understanding for improved learning potential and can motivate learning of technical concepts (such as mathematics [24]) by showing their practical use, relevant to students' careers. To address this need while still providing insight to complex materials engineering related problems, we developed several case studies to be used alongside GRANTA EduPack. There are two sub-categories of the Case Studies: Simplified and Advanced Industrial. The simplified case studies are two pages and provide a brief overview of an engineering or design problem. These are developed with first- and second-year courses in mind, with focus on one or two key topics. The simplified case studies include a short exercise set which can be used as assignments, group work or for in class discussion. The Industrial case studies are more advanced, going into detail of materials selection analysis and design objectives and constraints. A complete list of our current case studies is shown in Table 1 and can be found on our website.

Another set of active learning resources is focused on the Five Step Method by Professor Mike Ashby [25]. This method was originally created to address ideas of sustainability within design. 
Sustainability is becoming more and more important in materials science curricula. But the increased number of stakeholders and inputs in complex engineering and sustainability problems can be a daunting challenge for students. The Five Step Method was designed to help students think through these complicated problems in a systematic way. The five steps are shown in Figure 6.

Table 1: Current GRANTA EduPack Case Study List.

\begin{tabular}{|l|l|}
\hline \multicolumn{1}{|c|}{ Simplified } & \multicolumn{1}{c|}{ Advanced } \\
\hline \multirow{4}{*}{ Aluminum Strengthening } & Aerospace and Automotive Turbine Blades \\
\cline { 2 - 2 } & Biomaterials Selection for a Joint Replacement \\
\cline { 2 - 2 } Chainsaw & Mars Lander Heat Shield \\
\hline \multirow{4}{*}{ Stainless Steels } & Aerospace Pressure Vessels \\
\cline { 2 - 2 } & High-Performance Longboard Design \\
\cline { 2 - 2 } & Materials for a Tablet Device \\
\hline \multirow{4}{*}{ Longboard } & Truck Trailer Lightweighting \\
\cline { 2 - 2 } & Automotive Door Panels \\
\cline { 2 - 2 } & Biomedical Waste: Health vs. the Environment \\
\hline \multirow{4}{*}{ The Built Environment } & Suture Anchor Implant \\
\cline { 2 - 2 } & Porous Scaffolds for Bone Tissue Engineering \\
\cline { 2 - 2 } & Railway Lightweighting \\
\hline & Water Containers and Plastic Waste \\
\cline { 2 - 2 } & Material Properties and Structural Sections \\
\cline { 2 - 2 } & Electric Cars-Sustainability and Eco Design \\
\hline
\end{tabular}

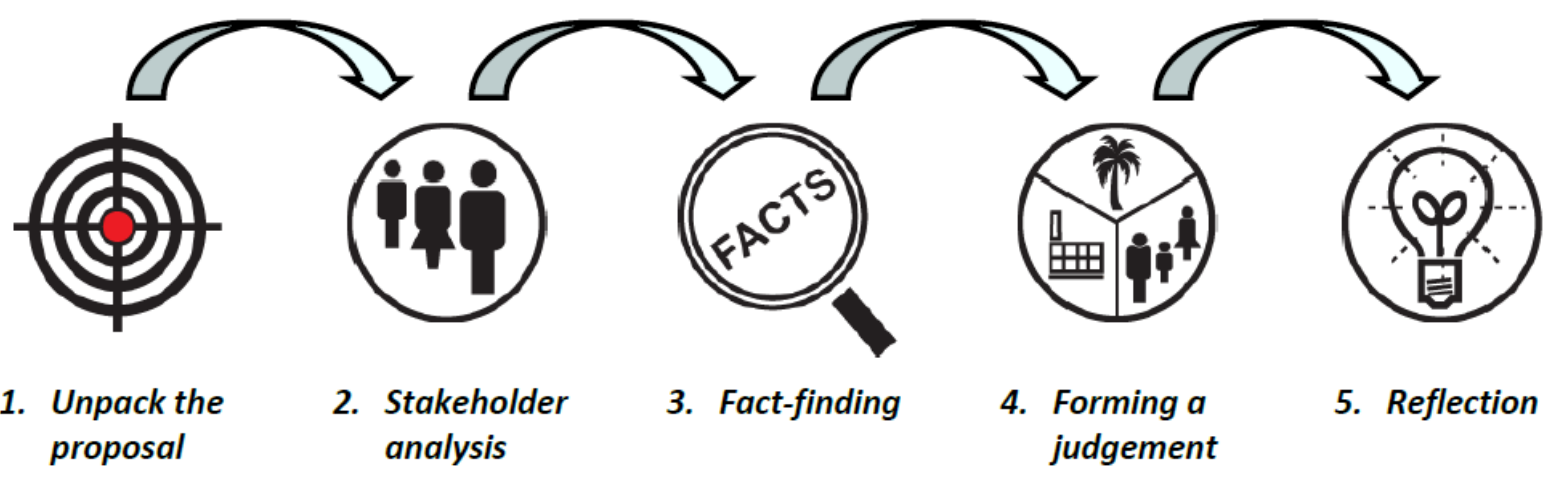

Figure 6: The Five Step Method developed by Professor Ashby and coworkers [25]

1. Unpacking the proposal-identifying timeline, objectives, and other key project objectives

2. Stakeholder analysis - Identifying stakeholders and their influence on the project outcomes

3. Fact finding - researching project and stakeholder needs

4. Forming a judgement - analyzing impacts of facts on the three capitals of sustainability 5. Reflection-looking at the outcome of fact analysis and determining if objectives are met

There is a wide variety of resources connected to this method (including user testimonies [26]); one is highlighted here. Recently, a Jigsaw framework was used to format a Five Step Method activity [27]. By forming groups where students were assigned knowledge areas in which to 
become experts, another avenue of learning was explored through teaching their peers [28]. Figure 7 shows one possible breakdown of the Five Step Method activities and how they would be used in a jigsaw activity. This idea of breaking into smaller groups then coming together as a class for discussion allows for several constructive and interactive activity moments within the whole problem analysis. While using a jigsaw-style application of the Five step method was originally focused on sustainability, the method itself can be translated across a range of activities, helping students break down complex problems and encourage discussion and collaborative learning.

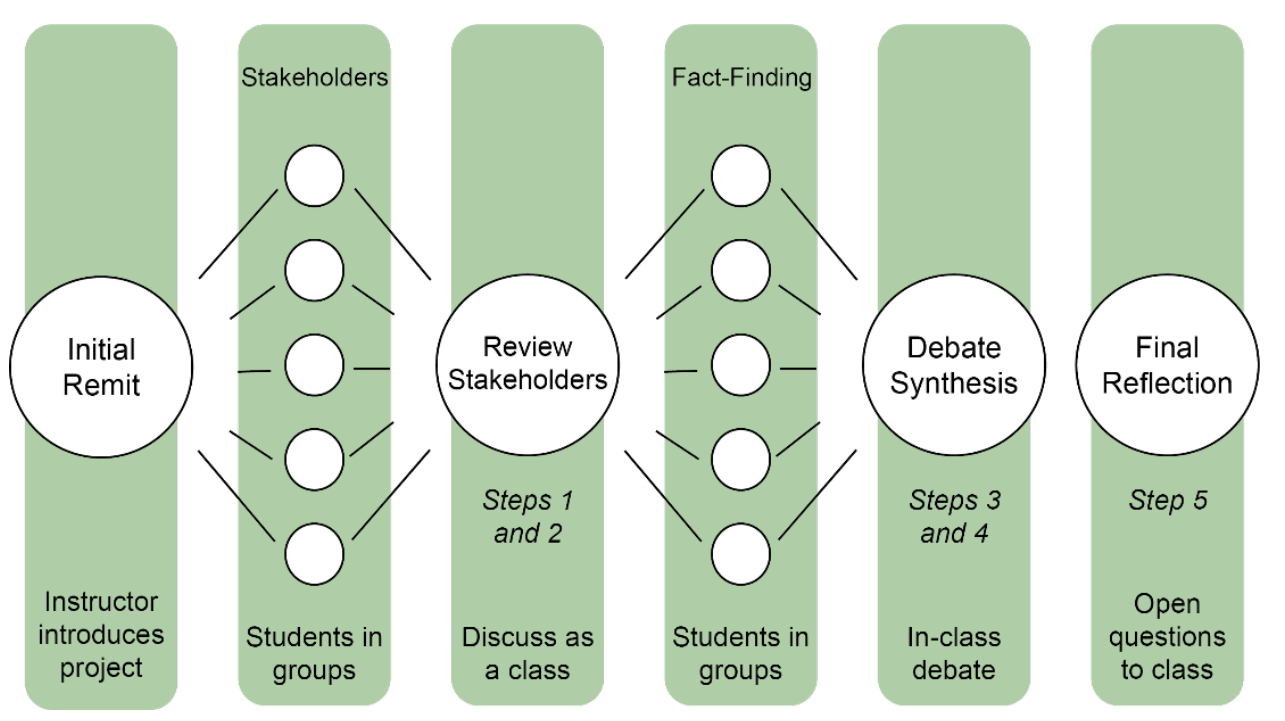

Figure 7: The Five-Step Ashby Method broken down in a Jigsaw Activity configuration

The final resource category we will highlight here is new to our resource hub are the Introductory Materials Science Teaching Packages. These were created specifically with active learning in mind. As mentioned previously, active learning has been shown to have an impact on student retention in introductory courses [18]. Introductory materials courses are also often shared between departments - materials science, mechanical, aerospace, and other majors could all be taking the same course. Active learning methods could be incorporated into these courses to help ensure that the students of the major understand the fundamentals and students outside the major understand the importance of materials within their fields. For this reason, four different topic areas (common to intro materials classes) were chosen as the focus for these teaching packages; these are:

(1) material families and bonding,

(2) crystallography,

(3) phase diagrams, and

(4) mechanical properties.

Each teaching package will contain:

(i) a lecture with associated notes and clicker questions,

(ii) a set of three microprojects,

(iii) a set of exercises,

(iv) a set of multiple-choice quiz questions, and 
(v) a set of three concept maps, an example of which can be found in Figure 8.

The manner in which atoms, moecules, or ions are spatially arranged<smiles>C=[V]</smiles>

Labeling conventions allow

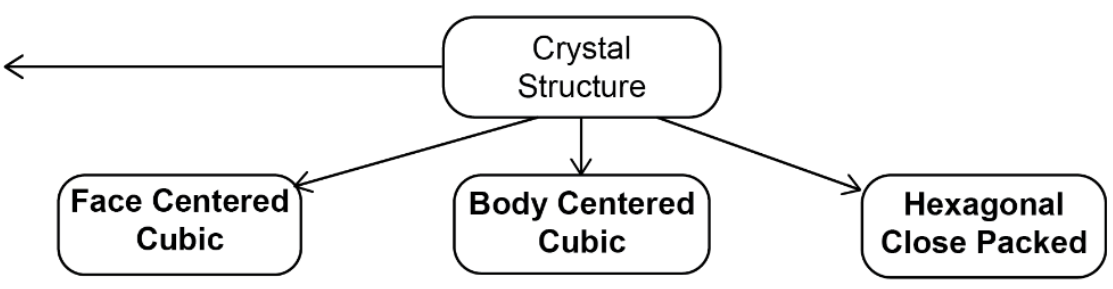
for identification of various aspects of unit cells

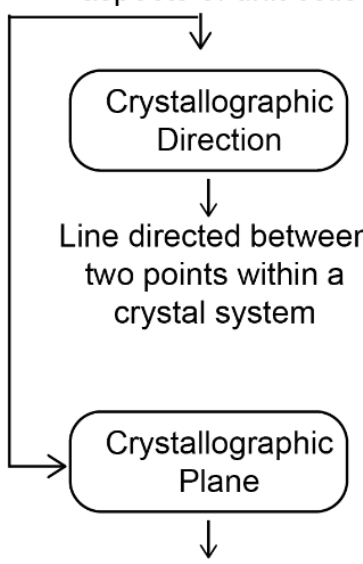

Two-dimensional planes of atoms within the unit cell
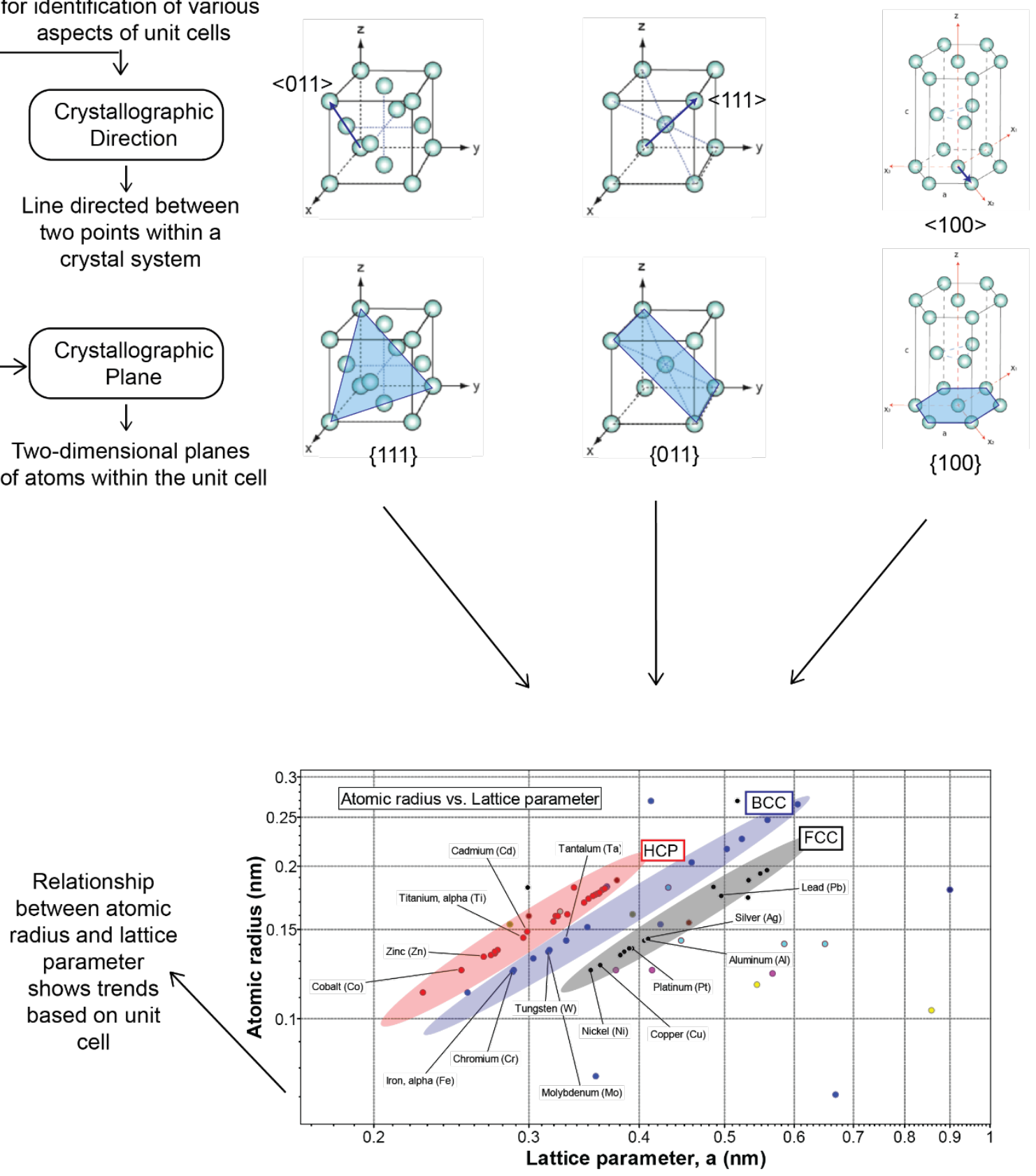
Figure 8: An example concept map from the Crystallography Teaching Package. Focus was given on connecting fundamentals (i.e. unit cells) with property relationships Additional support materials may be included, depending on the topic (i.e. a quick guide for reading/labeling planes and directions in the Crystallography Teaching Package). By providing a wide range of resources on the same topic, instructors can use the ones that fit best in their course curriculum, class culture, and teaching style. Giving students multiple resources for understanding one concept or topic can also be beneficial; it helps account for the varied learning backgrounds within introductory courses and can increase the chances of connecting with previous student knowledge. As these are new and partly still under development, only the phase diagrams package is currently available for download [29](at the time of publication), with the rest scheduled for release at the end of 2020.

With these coordinated software tools and resources, we hope to encourage instructors to explore teaching methods that go beyond the traditional lecture or seminar format and include more engaging activities.

\section{Next Steps}

As we develop these new resources, we continually reach out to the materials education community for advice and feedback. The teaching packages were developed to provide a cohesive pedagogical set of resources on specific topics [30]. The topics were chosen based on a survey of US introductory materials course syllabuses. As technology continues to become more prevalent within the classroom, we want to expand our resources to be easily incorporated. Are these the most beneficial topics and resources for today's educators? We look to you to guide us on further developing and improving these resources, so they are beneficial to the community as a whole.

\section{Conclusion}

Our understanding of how our students learn is evolving and with it, we are coming into a new age of higher education teaching, where more emphasis is being placed on increased student interaction within the classroom and acquiring professional skills, not just technical knowledge. Active learning helps address these future challenges by encouraging student interaction, both with the content and each other. There is ample support in the literature for beneficial outcomes with active learning, but student and faculty resistance can make implementation difficult. Ansys Granta is looking to encourage materials educators to incorporate active learning in their courses through software and associated resources. In this paper, the high degree of interactivity within the software and three sets of resources designed for active learning have been highlighted, as well as a call to the community for feedback on our newest teaching package resources. We hope to empower and support instructors including active learning in their materials science courses. 


\section{References}

[1] M. T. H. Chi, "Active-constructive-interactive: A conceptual framework for differentiating learning activities," Top. Cogn. Sci., vol. 1, no. 1, pp. 73-105, 2009.

[2] K. P. Cross, "Not can, butwill college teaching be improved?," New Dir. High. Educ., vol. 1977, no. 17, pp. 1-15, 1977, doi: 10.1002/he.36919771703.

[3] M. Prince, "Does active learning work? A review of the research," J. Eng. Educ., vol. 93, no. July, pp. 223-231, 2004, doi: 10.1038/nature02568.

[4] C. C. Bonwell and J. A. Eison, Active Learning: Creating Excitement in the Classroom. 1991 ASHE-ERIC Higher Education Reports. ERIC, 1991.

[5] S. Freeman et al., "Active learning increases student performance in science, engineering, and mathematics," Proc. Natl. Acad. Sci., vol. 111, no. 23, pp. 8410 LP - 8415, Jun. 2014, doi: 10.1073/pnas.1319030111.

[6] S. R. Hall, I. Waitz, D. R. Brodeur, D. H. Soderholm, and R. Nasr, "Adoption of active learning in a lecture-based engineering class," in 32nd Annual frontiers in education, 2002, vol. 1, pp. T2A-T2A.

[7] P. H. Kvam, "The effect of active learning methods on student retention in engineering statistics," Am. Stat., vol. 54, no. 2, pp. 136-140, 2000.

[8] ABET, "Criteria for Accrediting Engineering Programs, 2019-2020.” .

[9] J. D. Bransford, A. L. Brown, and R. R. Cocking, How people learn, vol. 11. Washington, DC: National academy press, 2000.

[10] M. Wolff, M. J. Wagner, S. Poznanski, J. Schiller, and S. Santen, "Not another boring lecture: engaging learners with active learning techniques," J. Emerg. Med., vol. 48, no. 1, pp. 85-93, 2015.

[11] W. B. Cutrer, D. Castro, K. M. Roy, and T. L. Turner, "Use of an expert concept map as an advance organizer to improve understanding of respiratory failure," Med. Teach., vol. 33, no. 12, pp. 1018-1026, 2011.

[12] K. A. Smith, T. C. Douglas, and M. F. Cox, "Supportive teaching and learning strategies in STEM education," New Dir. Teach. Learn., vol. 2009, no. 117, pp. 19-32, 2009.

[13] A. M. Rynearson and A. K. Polasik, "Interactive and Collaborative Materials Science and Processing Course with Integrated Lab,” 2019.

[14] K. L. Ruhl, C. A. Hughes, and P. J. Schloss, "Using the pause procedure to enhance lecture recall," Teach. Educ. Spec. Educ., vol. 10, no. 1, pp. 14-18, 1987.

[15] P. Laws, D. Sokoloff, and R. Thornton, "Promoting active learning using the results of physics education research," UniServe Sci. News, vol. 13, no. July, pp. 14-19, 1999.

[16] D. C. Owens, T. D. Sadler, A. T. Barlow, and C. Smith-Walters, "Student motivation from and resistance to active learning rooted in essential science practices," Res. Sci. Educ., pp. 1-25, 2017.

[17] L. Springer, M. E. Stanne, and S. S. Donovan, "Effects of small-group learning on undergraduates in science, mathematics, engineering, and technology: A meta-analysis," Rev. Educ. Res., vol. 69, no. 1, pp. 21-51, 1999.

[18] M. J. Graham, J. Frederick, A. Byars-Winston, A.-B. Hunter, and J. Handelsman, "Increasing persistence of college students in STEM," Science (80-. )., vol. 341, no. 6153, pp. 1455-1456, 2013.

[19] C. Bream and M. Ashby, "Introducing materials and processes to first and second year students," ASEE Annu. Conf. Expo. Conf. Proc., 2008. 
[20] M. F. Ashby, D. Cebon, and A. Silva, "Teaching engineering materials: the CES Edupack," Eng. Dep. Cambridge Univ., pp. 1-13, 2007.

[21] H. Melia, "New resources for introduction to materials class," ASEE Annu. Conf. Expo. Conf. Proc., vol. 2018-June, 2018.

[22] "Paper: The use of CES EduPack at all levels of Higher Education." [Online]. Available: https://grantadesign.com/teachingresources/papuheen18/. [Accessed: 02-Mar-2020].

[23] T. V Vakhitova and C. Fredriksson, "Practical competences as learning outcomes using ces edupack," J. Assoc. Eng. Educ. Russ., vol. 13, pp. 16-23, 2013.

[24] L. R. Mustoe and A. C. Croft, "Motivating engineering students by using modern case studies," Int. J. Eng. Educ., vol. 15, no. 6, pp. 469-476, 1999.

[25] M. F. Ashby, Materials and sustainable development. Butterworth-Heinemann, 2015.

[26] M. Ashby and T. V Vakhitova, "Teaching Package: Active-learning ToolKit- Sustainable Development," Granta Design Education Hub, 2017. [Online]. Available: https:/grantadesign.com/teachingresources/pacworen17/.

[27] K. A. Whalen and T. V Vakhitova, "Creating experiences, not lectures: experiential methods in the context of sustainable development teaching," EESD 2018, p. 322.

[28] D. L. Schwartz, J. M. Tsang, and K. P. Blair, The ABCs of how we learn: 26 scientifically proven approaches, how they work, and when to use them. WW Norton \& Company, 2016.

[29] “Teaching Packages," Granta Design Education Hub, 2020. [Online]. Available: https://grantadesign.com/education/teachingresources/package/.

[30] Z. V. Smirnova, O. I. Vaganova, L. B. Gatsalova, O. V. Golubeva, and E. A. Chelnokova, "Teaching Package Development for Engineering Training Programs," IOP Conf. Ser. Mater. Sci. Eng., vol. 483, no. 1, 2019, doi: 10.1088/1757-899X/483/1/012033. 